\title{
Koffi Kwahulé, dir. S. CHALAYE
}

\section{Emanuela Cacchioli}

\section{(2) OpenEdition \\ Journals}

Édition électronique

URL : https://journals.openedition.org/studifrancesi/32358

DOI : 10.4000/studifrancesi.32358

ISSN : 2421-5856

\section{Éditeur}

Rosenberg \& Sellier

\section{Édition imprimée}

Date de publication : 1 août 2020

Pagination : 448-449

ISSN : 0039-2944

\section{Référence électronique}

Emanuela Cacchioli, «Koffi Kwahulé, dir. s. chalaye », Studi Francesi [En ligne], 191 (LXIV | II) | 2020, mis en ligne le 01 septembre 2020, consulté le 16 septembre 2021. URL : http://journals.openedition.org/ studifrancesi/32358; DOI : https://doi.org/10.4000/studifrancesi.32358

Ce document a été généré automatiquement le 16 septembre 2021.

\section{(c) (†)}

Studi Francesi è distribuita con Licenza Creative Commons Attribuzione - Non commerciale - Non opere derivate 4.0 Internazionale. 


\title{
Koffi Kwahulé, dir. s. CHALAYE
}

\author{
Emanuela Cacchioli
}

\section{RÉFÉRENCE}

Koffi Kwahulé, dir. S. CHALAYE, Paris, Classiques Garnier, 2019, 323 pp.

1 Sylvie Chalaye, spécialiste de dramaturgie africaine, a dirigé un volume précieux dont les études francophones peuvent se nourrir pour découvrir en profondeur un écrivain hors du commun. Koffi Kwahulé est un intellectuel ivoirien né en 1956 qui a désormais atteint une très grande notoriété en Europe. Français d'adoption (il a 23 ans quand il arrive à Paris), l'auteur a gardé ses racines africaines, mais il a su s'approprier la langue française et les codes littéraires européens afin de créer une production complexe et perturbante. Romancier, conteur et notamment dramaturge, Koffi Kwahulé «a entrepris de faire sonner la langue française autrement et en a construit une œuvre déroutante, un continent inédit reconquis sur les terres de la postcolonie, un continent sombre et humain, fait de violence et d'amour, territoire immatériel, poétique et philosophique difficile à pénétrer» (p.7). L'écrivain ivoirien met au centre de sa production le thème de la traversée car il sous-entend toujours un déplacement. Ce sujet est traité à partir de plusieurs perspectives: le trajet historique et politique; le voyage existentiel et intérieur; le côté psychique et les rites de passage; la traversée physique, territoriale et par conséquent l'immigration, la rencontre avec l'Occident, le dépaysement culturel et la confrontation avec l'Autre. Les ouvrages de Kwahulé se focalisent autour de la construction d'une «conscience diasporique» (p.9) qui a entrepris un voyage sans retour et subit un partage impossible. Cette expérience angoissante est accompagnée de la violence: le viol, l'excision féminine, l'immolation, la mort sont des constantes des œuvres de l'écrivain. À côté de la cruauté physique, l'agression langagière frappe le lecteur et le réduit au silence, tout comme ses protagonistes qui vivent dans l'entre-deux d'un dédoublement identitaire: «Le migrant n'a d'autre territoire que lui-même, que son corps, sa mémoire, son imaginaire, sa force de création et au final son œuvre» (p. 13). 
2 Afin de suivre le parcours littéraire de cet écrivain et d'en saisir les particularités esthétiques, Sylvie Chalaye nous offre une première partie qui réunit les contributions critiques de quelques intellectuels ayant déjà consacré des études à ses ouvrages. Virginie SOUBRIER (pp. 19-32) considère la dimension jazz comme l'une des composantes majeures de «la dramaturgie noire» (p. 19) de Kwahulé. Selon le critique, l'altérité de ses pièces se manifeste notamment à travers la musicalité du langage et les aspects sonores qui constituent un élément récurrent de ses œuvres et de sa personnalité. Dominique TRAORÉ (pp. 33-54) se focalise sur les masques poétiques de son identité (plurielle et insaisissable), de son écriture (qui fait appel à une fable en mesure de dialoguer avec une histoire fragmentée) et de sa réception («dont la réinvention poétique entraîne inéluctablement des changements féconds», p. 54). Il s'agit d'une dramaturgie complexe qui se fonde sur un pacte de solidarité entre auteur et lecteur. Christophe колково (pp. 55-75) analyse ce qu'il définit l'esthétique de l'intermédialité, c'est-à-dire la dimension contemporaine du théâtre qui insère sur scène les médias audiovisuels ou électroniques pour raconter une identité dédoublée: auteur/ personnage, réalité/rêve. En effet, les œuvres de Kwahulé se caractérisent par ce processus de transformation «des sensations en écrits» (p. 75). L'article de Romuald FONKOUA (pp. 77-91) porte sur les enjeux littéraires de Monsieur Ki, un roman apparemment désordonné et extravagant qui célèbre l'art de l'écriture et nous propose quelques caractéristiques renouvelées du roman traditionnel africain. La danse est un autre élément fondamental des pièces de Kwahulé. Pierre LETESSIER (pp.93-120) en analyse cet aspect tout en mettant en relief qu'il s'agit d'une présence absente. Chez le dramaturge, la dimension chorégraphique se situe dans un théâtre de la parole avec une fonction particulière: la danse devient expression de l'altérité inscrite dans le corps, une pulsion qui démontre «un envers» dramaturgique (p. 105). La corporéité est également le sujet de l'article d'Isabelle ELIź́ON-HUBERT (pp. 121-131). La chercheuse et metteuse en scène nous montre les différentes formes de représentation du corps à l'intérieur d'un théâtre qui interroge l'altérité et la richesse de l'Autre. La contribution d'Agathe BEL-FRANKIAN (pp. 133-151) porte sur la truculence dans le sens d'«opérateur anthropologique de la conscience diasporique à l'œuvre» (p.134) passant par la traversée, le marronnage, la subversion et la vibration jazz. Le premier volet de l'ouvrage se termine par les réflexions d'Edwige GBOUABLÉ (pp. 153-165) qui interroge l'univers hybride de Kwahulé à partir de quatre points cardinaux: le dynamisme esthétique, l'écriture de l'altérité, la dramaturgie de la violence et la dimension politique.

3 La deuxième partie du volume, «Regards croisés» nous propose les témoignages des comédiens et des metteurs en scènes qui ont abordé la dramaturgie de Kwahulé et ont contribué à diffuser les œuvres de cet écrivain en France, en Afrique et dans le continent américain. Il s'agit d'une perspective intéressante qui permet de saisir une dimension originale du théâtre de l'écrivain ivoirien. La comédienne Dominique PAQUET (pp. 169) a d'abord connu Kwahulé comme acteur; elle en a ensuite mis en scène Jaz en 2003. Son article porte sur le rire, la musique, la violence et quelques enjeux esthétiques. Sébastien BOURNAC (pp.179-185) a, quant à lui, commandé la pièce $L a$ Mélancolie des barbares pour sa compagnie théâtrale et l'a finalement représentée à Toulouse en 2012. Sa contribution nous offre une lecture des aspects les plus sombres, en particulier la violence. Le metteur en scène de Big Shoot et Jaz, Alexandre ZEFF (pp. 187-200), nous propose un poème qui témoigne «sa relation sensitive et obsédante 
à l'écriture mystérieusement jazz et engagée» (p.179) de Kwahulé. Isabelle PousseUR (pp. 201-212) nous offre une chronique de l'expérience de création de L'Odeur des arbres entre février 2014 et janvier 2015. Kristian FRÉDRIC (pp. 213-220) relate sa première rencontre avec l'écrivain «boxeur des mots» (p. 213) en 2005.

La troisième section du volume est consacrée à deux textes inédits. Le premier, Madeleine (pp. 223-244), est une pièce théâtrale conçue comme variation de son œuvre précédente Ave Maria. L'autre inédit est un entretien («De l'autre rive du monde», pp. 245-267) que Kwahulé a accordé à Judith G. MILLER, sa traductrice américaine, en 2016. À travers les mots de l'écrivain, nous avons l'opportunité d'approfondir ses démarches esthétiques, ses enjeux créatifs, ses influences musicales, littéraires et cinématographiques, mais aussi de revenir sur ses origines, sa formation et son rapport avec l'Amérique.

5 Dans la dernière partie du volume, Sylvie Chalaye offre aux lecteurs une biographie complète et exhaustive (pp. 269-280) de ses données personnelles, mais aussi de ses créations littéraires et de tous les projets qui concernent l'exploitation de ses œuvres et la mise en scène de son théâtre. Une section consacrée à la bibliographie complète des œuvres de Koffi Kwhaulé, de ses traductions, mais aussi des émissions radiophoniques et des enregistrements télévisuels (pp. 281-290) complète la biographie de l'écrivain. L'ouvrage se termine par une riche bibliographie critique (pp. 291-301) qui permet de saisir l'intérêt que l'intellectuel ivoirien a déjà suscité au sein des études francophones.

Koffi Kwahulé est un volume précieux pour tout chercheur qui désire connaître et approfondir les démarches esthétiques d'un écrivain contemporain complexe qui choisit la marge pour raconter l'entre-deux avec sa douleur, mais également sa force créatrice. 